\title{
“Discordant Airflow Obstruction: GOLD versus LLN"
}

\author{
Martin R. Miller \\ Institute of Occupational and Environmental Medicine, University of Birmingham, Birmingham B15 2TT, UK \\ Correspondence should be addressed to Martin R. Miller, m.r.miller@bham.ac.uk \\ Received 16 May 2012; Accepted 10 June 2012 \\ Copyright (C) 2012 Martin R. Miller. This is an open access article distributed under the Creative Commons Attribution License, \\ which permits unrestricted use, distribution, and reproduction in any medium, provided the original work is properly cited.
}

I recently came across the paper of Lamprecht et al. "Subjects with discordant airways obstruction: lost between spirometric definitions of COPD" which deals with people who are defined as having COPD by the GOLD criteria [1] but not by using a lower limit of normal (LLN) method. The authors found this discordant group had fewer symptoms and less severe $\mathrm{FEV}_{1}$ impairment than those diagnosed with obstruction by both methods, and so the discordant group did not have clinically significant airway obstruction. However, they conclude that this discordant group had a clinical profile characterised by relevant comorbid disease, namely, more heart disease. The analysis they present does not allow for their conclusion that the GOLD criteria on lung function in some way specially identifies this risk, because the authors failed to account for other relevant covariates in their analysis. The discordant group is known to be biased towards men and older subjects by the way the fixed ratio of $\mathrm{FEV}_{1} / \mathrm{FVC}<0.7$ discriminates against them versus the LLN [2]. In their analysis the authors have accounted for the age differences between the groups but not for the observed sex differences; namely, men accounted for $81.5 \%$ of the discordant group but were only $48.7 \%$ of the concordant group. Since heart disease is more prevalent in men, the authors' results cannot be used to suggest that identifying their discordant group from lung function testing in some way specially identifies those at risk of heart disease. It just introduces a male bias.

\section{References}

[1] K. F. Rabe, S. Hurd, A. Anzueto et al., "Global strategy for the diagnosis, management, and prevention of chronic obstructive pulmonary disease: GOLD executive summary," American Journal of Respiratory and Critical Care Medicine, vol. 176, no. 6, pp. 532-555, 2007.
[2] W. M. Vollmer, P. Gíslason, P. Burney et al., "Comparison of spirometry criteria for the diagnosis of COPD: results from the BOLD study," European Respiratory Journal, vol. 34, no. 3, pp. 588-597, 2009. 


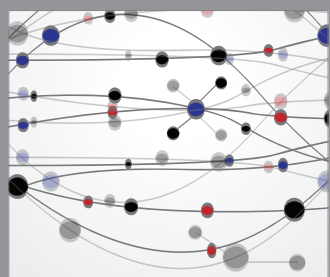

The Scientific World Journal
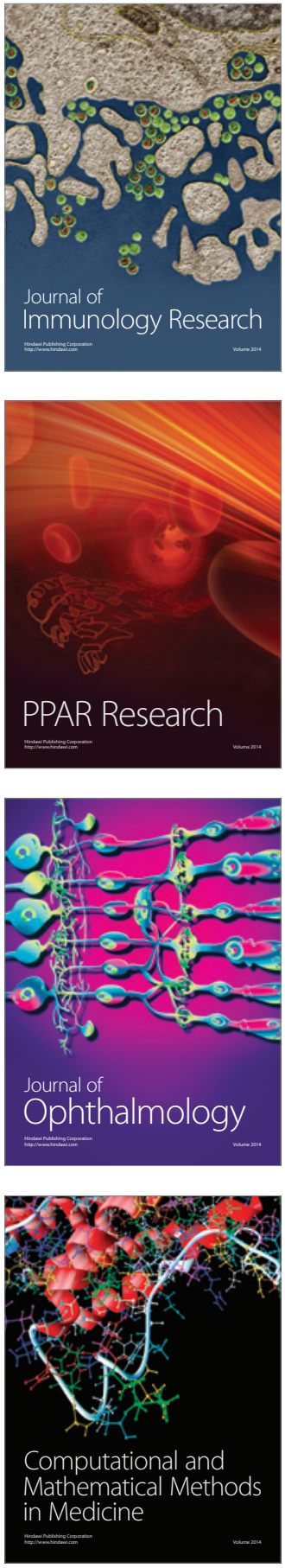

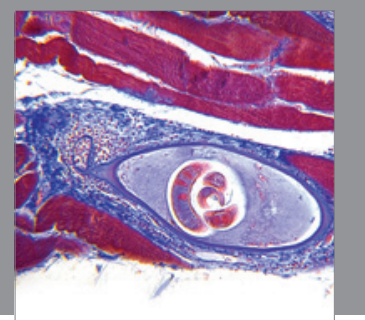

Gastroenterology

Research and Practice
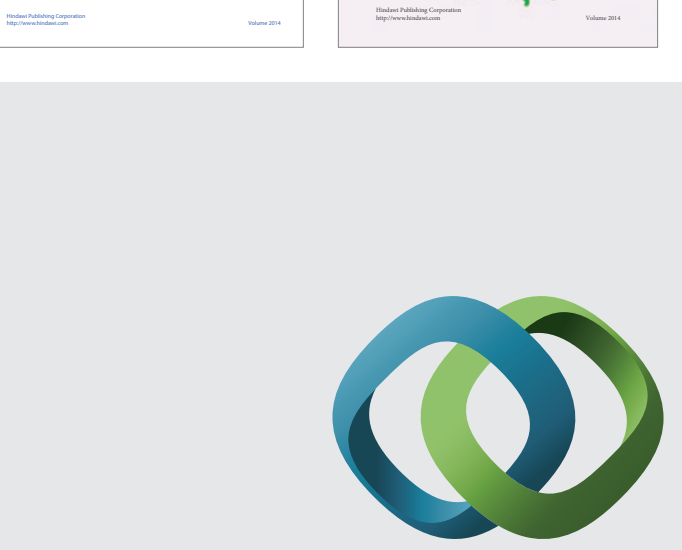

\section{Hindawi}

Submit your manuscripts at

http://www.hindawi.com
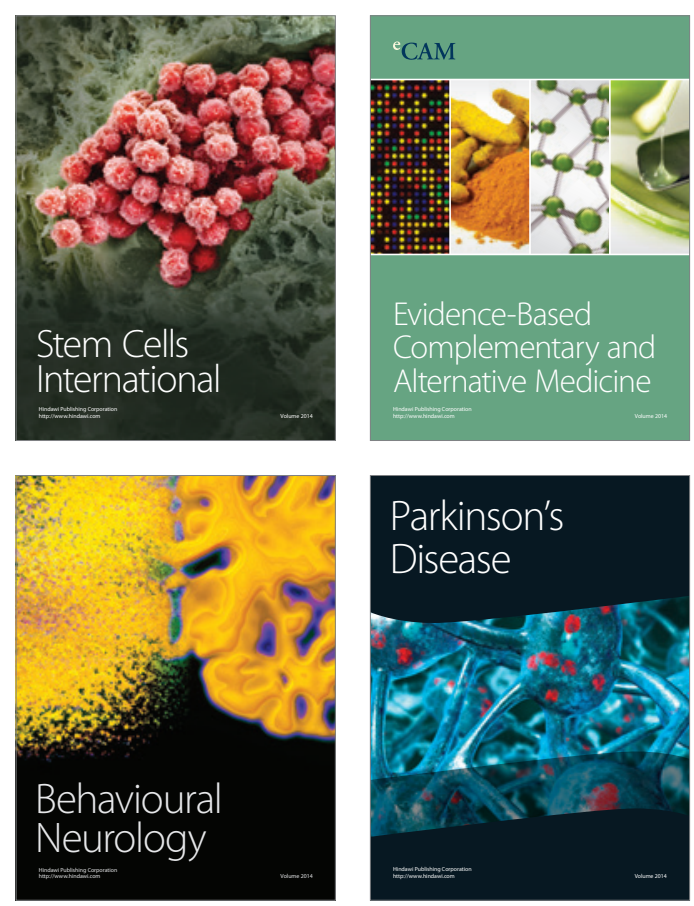

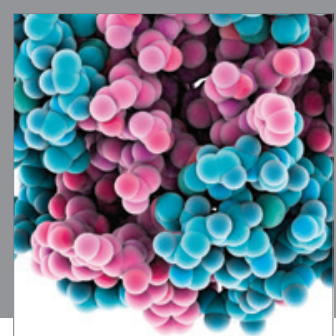

Journal of
Diabetes Research

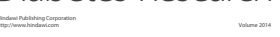

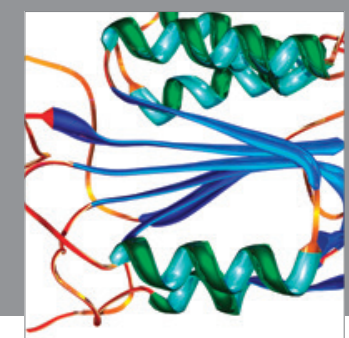

Disease Markers
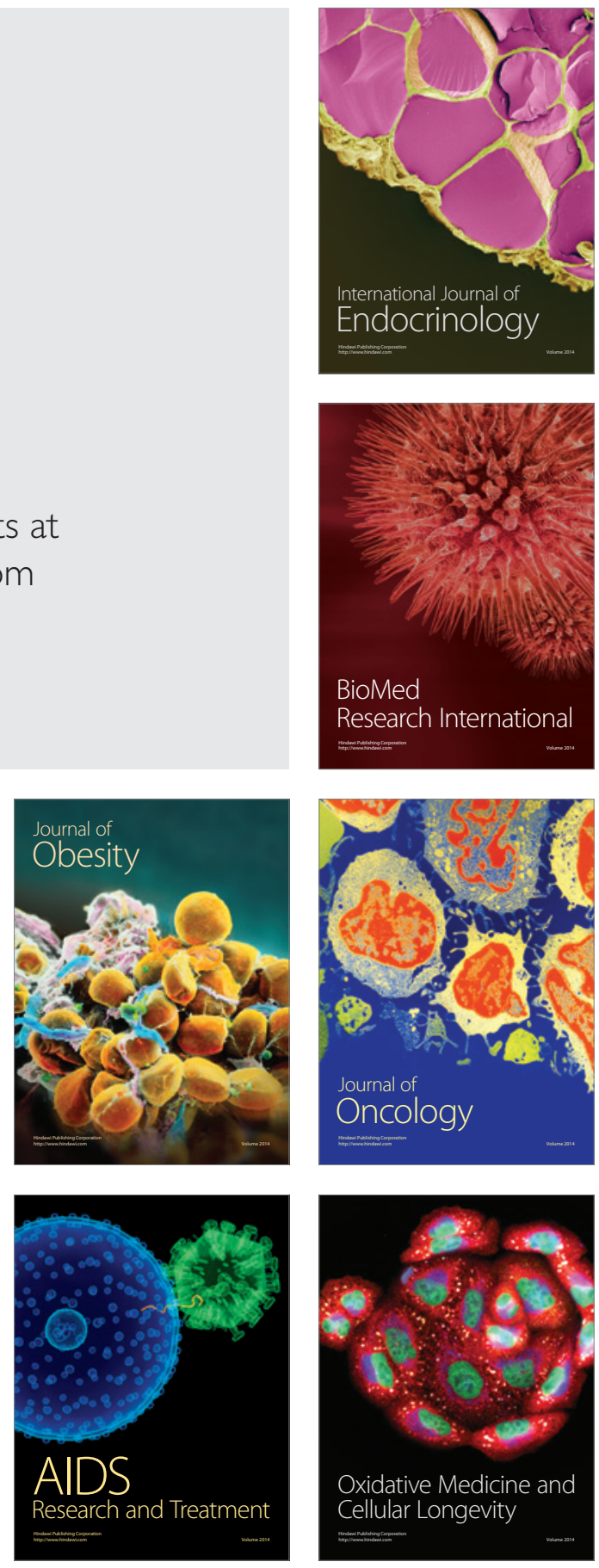